\section{ALINHAMENTO ESTRATÉGICO DE UMA CONCESSIONÁRIA DE ENERGIA ELÉTRICA E SUAS EMPRESAS TERCEIRIZADAS: ESTUDO DESCRITIVO PÓS-IMPLANTAÇÃO DE INDICADORES DE DESEMPENHO}

\section{RESUMO}

No cenário de internacionalização das economias, o advento das modernas formas de gestão suscita a adoção de novos modelos institucionais que estimulem a competitividade das empresas brasileiras. Entre essas mudanças, tem-se a privatização do setor elétrico e a emergência do modelo de gestão por terceirização com a finalidade de promover a redução de custos, economia de recursos e descentralização de atividades. A partir dessa temática, delineia-se como objetivo analisar o alinhamento estratégico entre empresas terceirizadas e uma concessionária de distribuição de energia elétrica por meio de indicadores de desempenho. Para tanto, utiliza-se de pesquisa descritiva mediante base de dados secundária, na qual constam informações provenientes de pesquisa de monitoramento de indicadores de 12 empresas terceirizadas de uma distribuidora de energia elétrica, além das informações da pesquisa de clima de 1800 colaboradores. Os principais resultados evidenciam melhoria do negócio das empresas terceirizadas e da distribuidora, sobretudo, pelo fato do modelo de avaliação implantado promover maior aproximação entre contratante e contratadas o que permite melhor sincronismo no alinhamento estratégico dessas empresas.

Palavras-chave: Alinhamento estratégico. Terceirização. Setor elétrico.

\section{INTRODUÇÃO}

A última década do século XX foi marcada por diversas mudanças no Brasil, em que, de um lado, a internacionalização impulsionou a abertura da economia e, de outro, a Constituição de 1988 estabeleceu um novo marco institucional. Nesse contexto, tem-se a implementação de modelos de gestão que têm como finalidade estimular a competitividade das empresas e o enfrentamento das novas condições impostas pelo mercado nacional. Entre essas mudanças de gestão, destacam-se a reestruturação produtiva e a privatização associada com a terceirização de grande parte das atividades do setor elétrico brasileiro. 
Segundo Druck e Borges (2002) apud Costa (2012), reestruturação produtiva é entendida como um conjunto de mudanças na produção e no trabalho, por meio da tecnologia e da implementação de novos processos de gestão e organização do trabalho. D'Araújo (2009) e Giosa (2007) definem a privatização como o processo de venda de uma empresa ou instituição do setor público para a iniciativa privada na qual esta repassa algumas atividades para terceiros. A partir daí, tende a ser estabelecida uma relação de parceria, passando a organização a concentrar-se no core business do negócio em que atua.

Os autores ainda reafirmam que a terceirização enquadra-se em um modelo de gestão que prevê a redução de custos, economia de recursos e descentralização de atividades. Dessa maneira, uma das exigências estabelecidas pelas empresas contratantes junto às empresas contratadas é de que essas atinjam os níveis de qualidade, de credibilidade e de segurança que permitam a obtenção de eficiência e eficácia na execução dos trabalhos. Nessa perspectiva, a privatização torna-se uma das melhores alternativas para viabilizar ganhos de vantagem competitiva e volume de mercado.

Sob essa perspectiva, entende-se que a diminuição de custos, a otimização de recursos e a descentralização de atividades estão diretamente relacionados à Gestão Estratégica por Resultados (GPR) que, por sua vez, é reflexo do alinhamento estratégico da empresa. Luftman (2000) apud Vreuls e Joia (2012) define alinhamento estratégico como uma série de atividades executadas coordenadamente pelos gestores de uma empresa com o objetivo de alcançar metas por meio da coordenação de várias áreas funcionais. Assim, o objetivo deste artigo é analisar o alinhamento estratégico entre uma concessionária de distribuidora de energia elétrica e suas empresas terceirizadas a partir da gestão de indicadores de desempenho.

Para tanto, utiliza-se de pesquisa descritiva mediante base de dados secundária, na qual constam informações provenientes de pesquisa de monitoramento de indicadores de 12 empre- sas terceirizadas de uma distribuidora de energia elétrica, além das informações da pesquisa de clima de 1800 colaboradores. A pesquisa primária foi aplicada nos anos de 2013 e 2014 para avaliar o nível de alinhamento estratégico em prestadoras de serviços e a empresa contratante por meio do modelo de indicadores de desempenho compatível com a proposta Barreto (2005).

No campo dos estudos estratégicos, a gestão por indicadores encontra no presente trabalho uma relevante contribuição. Por fazer parte de uma realidade de mudança, a terceirização possui particularidades que ainda não foram objeto de estudo, devendo ser analisadas do ponto de vista acadêmico, a fim de que seja construída a relação com as áreas da gestão já existentes, podendo-se destacar estratégia, o marketing e a gestão de pessoas no contexto terceirizado. Do ponto de vista de método, este estudo constitui-se a partir da modelagem de Barreto (2005) que, uma vez aplicado, torna-se objeto de estudo para que sejam denotadas contribuições no ambiente de empresas do setor elétrico. Já em termos práticos, há as melhorias na prestação de serviços, sobretudo quanto à segurança e a disponibilidade do fornecimento elétrico, impactando na satisfação do consumidor e na otimização das exigências contratuais que possibilitem melhorias para os envolvidos, no caso, fornecedora, contratadas e clientes.

Ademais, o artigo contempla além dessa introdução, outras sete seções. Nas seções dois, três e quatro discorre-se acerca do arcabouço teórico que embasa o estudo. Em seguida, tem-se a metodologia utilizada no desenvolvimento da pesquisa. A partir daí, então, são apresentados os resultados da parte empírica do trabalho e, finalmente, são delineadas as conclusões.

\section{BASES DA TERCEIRIZAÇÃO}

A terceirização é uma prática de gestão estratégica que vem evoluindo gradativamente, passando de uma situação de mera transferência de atividades operacionais e de pouca importância, para uma situação de integração entre a empresa contratante e a contratada, na 
qual se estabelece um relacionamento de parceria permitindo o alinhamento dos objetivos e o alcance dos resultados esperados.

Para Marcelino (2007), terceirização é todo processo de contratação de trabalhadores por empresa interposta, em que se tem uma relação em que o trabalho é realizado para uma empresa, mas contratado de maneira imediata por outros. Além disso, de acordo com Barreto (2005), embora se considere a concessão como um contrato intuitu personae, a lei admite a contratação de terceiros para a execução de atividades inerentes, acessórias ou complementares ao serviço concedido.

Valença e Barbosa (2002) argumentam que há três propósitos básicos pelos quais as organizações decidem terceirizar: o primeiro deles seria a diluição dos custos diretos e indiretos das atividades desempenhadas; em segundo, a elevação do nível de eficiência dessas atividades, por sua execução terceirizada e, por fim, a manutenção de um nível mínimo aceitável de lealdade à empresa, por parte dos novos executores das atividades terceirizadas por meio do contrato firmado.

Corroborando, Miranda (2011) e Giosa (2007) argumentam que a contratação de empresas especializadas em atividades específicas vem sendo praticada por empresas que buscam gerar melhores resultados. Nesse sentido, para a organização alcançar esses objetivos, a empresa contratante deve estimular o alinhamento da visão e da estratégia das contratadas. Segundo os mesmos autores, a empresa contratante deve ter um bom relacionamento, com base em parceria e na confiança, em que a contratada possui autonomia para tomar suas decisões operacionais, mantendo, entretanto, uma troca de informações contínua com a contratante.

A escolha das empresas que prestarão o serviço é uma etapa importante e deve ser feita com base em elementos não apenas financeiros. Valença e Barbosa (2002) chamam a atenção para o fato de que, para se trabalhar com culturas organizacionais diferentes, uma das empresas, ou ambas, tem que adaptar-se, efetuando ajustes, a partir de entendimentos acerca de suas diferenças culturais. No entendimento desses autores, é possível inferir que a terceirização poderá trazer mudanças para a cultura das empresas, o que pode colocar, ou não, a sobrevivência e o aperfeiçoamento organizacional em risco, tudo isto a depender da forma como seja conduzida a implantação do modelo terceirizado.

Dessa forma, Kardec (2002) orienta que, para que o instrumento da terceirização seja capaz de gerar resultados positivos, quatro pontos precisam ser observados:

a) ter sua atividade bem definida;

b) estar tecnologicamente atualizada;

c) dispor de ferramentas e equipamentos adequados e;

d) dispor de recursos humanos e processos.

A partir dessa escolha, tem-se o primeiro passo para uma gestão por indicadores alinhada à estratégia da contratante e uma contratação capaz de gerar melhores resultados.

Não obstante, apesar de a terceirização gerar em linhas gerais bons resultados para a empresa contratada esse, como qualquer outro modelo de gestão, tende a apresentar vantagens e desvantagens. Acerca do assunto, Giosa (2007) argumenta que a prática da terceirização influencia diretamente nos resultados operacionais da empresa, contribuindo para o aumento da produtividade, eficiência e lucratividade. Entretanto, quando se terceiriza sem uma adequada visão estratégica, tal postura pode implicar em desvantagens ao longo de processo.

A partir desse entendimento, o autor apresenta uma série de itens que se caracterizam como vantagens e desvantagens competitivas proporcionadas pela prática da terceirização, conforme exposto no Quadro 1. 


\begin{tabular}{|l|l|}
\hline \multicolumn{1}{|c|}{ Vantagens } & \multicolumn{1}{|c|}{ Desvantagens } \\
\hline Menor custo e tendência a maior lucratividade; & Desconhecimento da Alta Administração; \\
Especialização dos serviços; & Resistência e conservadorismo; \\
Competitividade; & Dificuldade de se encontrar o parceiro ideal; \\
Busca da Qualidade; & Risco de coordenação dos contratos; \\
Controle adequado; & Falta de parâmetros de custos internos; \\
Aprimoramento do sistema de custeio; & Custo de demissões; \\
Diminuição do desperdício; & Conflitos com os Sindicatos; \\
Agilidade das decisões; & Desconhecimento da legislação trabalhista. \\
Esforço de treinamento e desenvolvimento de pessoal; & \\
Valorização dos talentos humanos. & \\
\hline
\end{tabular}

Quadro 1 - Vantagens e desvantagens da terceirização

Fonte: adaptado de Giosa (2007, p. 85).

No Quadro I, são confrontados os elementos principais que devem ser avaliados em detalhes em caso de uma decisão por terceirizar um processo, empresa ou setor. Entre as vantagens evidenciadas, destaque-se o menor custo, o controle adequado e a agilidade nas decisões e, por outro lado, o custo de demissões, o conflito com sindicatos e o risco na coordenação dos contratos surgem como fatores desfavoráveis a esse modelo de gestão. Nessa perspec- tiva, a terceirização exige um plano prévio e uma constituição contratual bem definida, uma vez que essas desvantagens desfocam o núcleo central das atividades da organização, tornando sem sentido o efeito de terceirizar.

Os autores Guimarães e Carvalho (2012) trazem essa perspectiva em termos de riscos e benefícios a que estão submetidas as empresas que adotam o processo de terceirização, conforme Quadro 2.

\begin{tabular}{|l|l|}
\hline \multicolumn{1}{|c|}{ Riscos } & \multicolumn{1}{c|}{ Benefícios } \\
\hline Perda de controle e flexibilidade; & Foco nas competências centrais e distintivas; \\
Dependência do fornecedor; & Acesso a especialistas; \\
Problemas de comunicação; & Redução de custos; \\
Perda de reputação; & Adaptabilidade a necessidades internas; \\
Exposição à violação de conformidade; & Capacidade de inovação; \\
Custos "escondidos"; & Menor volatilidade no investimento tecnológico; \\
Problemas de rotação e qualidade; & Resposta a aumento de volume e capacidade; \\
Descontinuidade/inconsistência do serviço; & Melhor serviço ao utente; \\
\hline
\end{tabular}

Quadro 2 - Riscos e benefícios da terceirização

Fonte: Guimarães e Carvalho (2012, p. 1181).

Guimarães e Carvalho (2012) desenvolvem a perspectiva de riscos e benefícios, sintetizada no Quadro 2, em que a capacidade de inovação, o acesso a especialistas e possibilidade de foco nas competências centrais do negócio elevam o nível de importância da terceirização para as atividades da organização, desde que haja comunicação efetiva entre contratante e fornecedora, continuidade no fornecimento dos serviços e boa manutenção da imagem da empresa por parte da contratada - a quem esta representa, elementos que devem ser tratados previamente nos acertos técnicos e contratuais.

Em se tratando dos benefícios, é importante considerar que esses tendem a implicar alavancagem de desempenho o que gera resultados superiores para as empresas contratantes. Há de se notar, ainda, que esses argumentos vão 
de encontro às proposições de Giosa (2007) acerca de fatores que determinam o êxito da terceirização; vale destacar para este estudo, a importância dada pela empresa contratante de garantir um alinhamento estratégico com as empresas contratadas. Uma vez conseguida esta sincronia estratégica, muitas dificuldades na gestão e nos resultados são superadas e a parceria pode resultar em um excelente negócio, como será visto adiante.

\section{ALINHAMENTO ESTRATÉGICO E ADMINISTRAÇÃO POR OBJETIVOS}

A gestão estratégica tem-se tornado uma das características das empresas bem-sucedidas em seus negócios, independente do setor de atuação ou do tipo de negócio. Nessa busca contínua pela melhoria, é importante destacar a importância da delimitação das metas a serem concretizados pelas organizações tendo em vista o alcance dos objetivos organizacionais. Dessa forma, a gestão estratégica torna-se desafiadora por buscar ir além do estabelecimento das metas organizacionais e conduzindo a empresa de forma mais assertiva dentro do complexo dinamismo e das mudanças rápidas do ambiente externo.

Kaplan e Norton (2006) e Rezende (2009) alertam para o fato de que dois terços das organizações por eles estudadas não criam, ou criam deficientemente, um forte alinhamento entre suas estratégias e os programas de recursos humanos e de tecnologia da informação, causando perda na eficiência dos investimentos, uma vez que estes, por si só, não seriam capazes de colocar a estratégia em ação.

Para Cavalcanti (2007), a Gestão Estratégica é uma forma de acrescentar novos elementos de reflexão e ação sistêmica e continuada. $\mathrm{O}$ autor reafirma que sua finalidade está ligada à avaliação da situação, elaboração de projetos de mudanças estratégicas e acompanhamento e gerenciamento da implementação dessas melhorias. Em outras palavras, tem-se uma forma de gerir toda a organização, com foco em ações estratégicas por suas diversas áreas, de maneira coordenada.

Corroborando esta ideia, Campos (2005) complementa que para se atuar com Gestão Estratégica, faz-se necessário uma apuração de todos os processos e a real situação da empresa. A partir da montagem desse panorama organizacional, é possível desenvolverem-se ações corretivas constantes, focando seus objetivos e metas e desenvolvendo estratégias de forma a manter sua sobrevivência, crescimento e diferenciação competitiva. Esse caráter de temporalidade contínua configura uma característica importante para a manutenção de um patamar de qualidade dos produtos, serviços e processos da empresa, evitando dispersões.

Beer e Eisenstat (1996) apud Cummings e Worley (2015) argumentam que o Alinhamento Estratégico e a Contratualização de Desempenho (Acordo para Objetivos e Resultados) referem-se à complexidade e interdependência de um sistema aberto. Nesses tipos de sistemas, diversos elementos interagem entre si e o meio externo, destacando-se os formais, como tecnologia, estratégia e estrutura, - e os informais, como as pessoas, líderes e valores. Assim, conforme os autores é indispensável avaliar o sistema organizacional aberto como um todo, e não somente departamentos ou setores, identificando e alinhando as variáveis externas e internas, formais e informais que influenciam nos processos existentes na organização.

Ainda na perspectiva de sistema aberto, reafirma-se que a orientação da empresa para e pela estratégia remete à necessidade de maiores níveis de efetividade e alinhamento entre os mecanismos de gestão estratégica adotados e os setores da organização. Ao mesmo tempo, requer a adoção de sistemáticas de gerenciamento do desempenho capazes de integrar, por meio do enfoque de perspectivas múltiplas, as expectativas e interesses dos stakeholders. (REZENDE, 2009).

$\mathrm{Na}$ evolução deste raciocínio, Kaplan e Norton (2000) citam a expressão administração estratégica defendendo o alinhamento de recursos organizacionais, processos e posicionamento estratégicos. Para este mesmo autor, inicialmente os recursos organizacionais seriam aproximados de seus processos críticos e, 
na sequência, os dois anteriores com o posicionamento estratégico.

Conforme afirma Lodi (1974) apud Hourneaux Junior, Ruiz e Corrêa (2005, p. 5), "a administração por objetivos (APO) é um método de planejamento e controle administrativo, baseado na premissa de que, para atingir resultados, a empresa precisa definir em que negócio está e onde pretende chegar". Dias et al. (2013) reafirmam que a APO foi proposta inicialmente nos trabalhos de Peter Drucker, que concebeu a ideia de que uma empresa deveria ter um grupo especial determinando suas estratégias e fixando os objetivos. Esse movimento prevê que os administradores devem identificar, em conjunto, metas, e definir responsabilidades baseadas nos objetivos organizacionais. (DIAS et al., 2013).

Assim, diante do surgimento da APO, os objetivos passaram a ser definidos com a participação dos colaboradores, com a implicação de que tanto os colaboradores quanto os gerentes seriam avaliados em seu desempenho no cumprimento desses referidos objetivos. Nesses termos, Kwasnicka (2006) corrobora que essa descentralização das decisões conduz à fixação de objetivos para cada área-chave, o que leva à centralização de controles voltada para os objetivos gerais das empresas.

(2010) acrescenta que a APO é um estilo exigente e compensador de administração de empresas. Os gerentes e subordinados, em conjunto, nessas definições de metas comuns, especificam as áreas principais de responsabilidade de cada posição em relação aos resultados. A partir do que é definido, estabelecem-se as medidas e os indicadores como guias para a verificação do desempenho do indivíduo e sua contribuição em relação ao cumprimento dos objetivos organizacionais.

Ademais, é interessante observar que a APO enfatiza a quantificação e a mensuração para monitorar/controlar se os resultados ou objetivos atingidos são compatíveis com os objetivos planejados anteriormente. Para Kaplan e Norton (2006), a mensuração e o controle constituem as maiores dificuldades para sua implantação. Segundo os autores, a adoção de um sistema conju- gado de indicadores e medidas é a solução para obter o equilíbrio dos objetivos organizacionais em um conjunto harmonioso e sistêmico.

\section{INDICADORES DE DESEMPENHO}

Nascimento, Bortoluzzi e Dutra (2009) descrevem que, no contexto atual, a avaliação de desempenho tem-se tornado instrumento fundamental na gestão das organizações frente ao ambiente de mudanças e à competitividade em que as empresas estão inseridas. Os autores Machado Márcia, Machado Márcio e Holanda (2007) afirmam que a mensuração do desempenho tem como objetivo principal ser um instrumento de gestão capaz de proporcionar um gerenciamento eficaz da organização, e este é dependente de uma série de variáveis, como: bases informativas, variáveis consideradas, critérios, conceitos e princípios adotados. (NASCIMENTO, BORTOLUZZI E DUTRA, 2009).

Assim, a avaliação é influenciada principalmente pelos objetivos e as metas da empresa, as quais se refletem no exercício do controle e estão correlacionados com as fases de execução e planejamento das atividades da empresa. Dessa forma, o efetivo acompanhamento do desempenho organizacional requer a adoção de um conjunto de parâmetros que traduzam os objetivos em valores mensuráveis. Em sentido amplo e denotativo, Rossetti e Andrade (2012) definem indicadores de desempenho como dados ou informações, preferencialmente numéricos, que representam um determinado fenômeno e que são utilizados para medir um processo ou os resultados.

Segundo Oliveira (2008), um indicador de desempenho constitui-se em um parâmetro e um critério de avaliação previamente estabelecido, que permite a verificação da realização, bem como da evolução da atividade ou do processo na empresa. Essas considerações ganham destaque em um ambiente competitivo, em que o executivo requer significativamente melhores condições e medidas para definir e dirigir as estratégias e o desempenho das organizações, conforme reafirmam Krugman e Obstfeld (2007). 
Nesse sentido, uma empresa necessita de instrumentos que possam, de um lado, indicar seu desempenho e, de outro, de indicadores que possam gerar informações para que avalie sua posição diante do mercado e diante dela mesma. Segundo Kaplan e Norton (2004, p. 7), "o que é medido é conseguido". Os autores afirmam que os sistemas de mensuração exercem forte influência sobre o comportamento de gerentes e empregados, e que a utilização tão somente de indicadores tradicionais de desempenho financeiro torna-se obsoleta diante da realidade dinâmica dos mercados contemporâneos.

Os autores Machado Márcia, Machado Márcio e Holanda (2007) apud Nascimento, Bortoluzzi e Dutra (2009) reafirmam que medição do desempenho tem como objetivo maior ser um instrumento de gestão capaz de proporcionar um gerenciamento eficaz da organização, instrumento que é dependente de uma série de variáveis, como: bases informativas, variáveis consideradas, critérios, conceitos e princípios adotados. Dessa forma, a avaliação será influenciada principalmente pelos objetivos e pelas metas da empresa que se refletem no exercício do controle, sendo correlacionados com as fases de planejamento e execução das atividades da empresa.

Sem medidas de desempenho, os gestores de uma organização não possuem fundamentos suficientemente consistentes para:

a) comunicar aos colaboradores as expectativas de desempenho da organização;

b) saber o que está acontecendo em cada área da organização;

c) identificar os aspectos deficientes e/ ou eficientes no desempenho da organização, a fim de eliminá-los ou fazer sua revisão;

d) fornecer feedback aos colaboradores que demonstrem desempenho aquém do planejado; (v) identificar os aspectos que apresentem melhor desempenho e;

e) tomar decisões baseadas em informações sólidas, transparentes e que possam ser justificadas. (DUTRA, 2003)
Para Machado, Machado e Holanda (2007), os indicadores de desempenho passam a ter um papel central nas organizações para o processo de tomada de decisões, sendo influenciados, principalmente, pelos objetivos e pelas metas das organizações. Assim, uma característica que deve ser levada em consideração está relacionada com a equivalência dos indicadores, já que esses devem respeitar os demais objetivos organizacionais. Segundo os autores, os indicadores necessitam de três componentes básicos para serem construídos a fim de que possam viabilizar o monitoramento do desempenho organizacional.

Neste sentido, os autores definem:

a) índice - valor numérico do indicador (relação matemática) em um determinado momento;

b) referencial comparativo - índice arbitrado (atribuído) ou convencionado para o indicador;

c) meta - índice arbitrado para o indicador a ser alcançado em um determinado período de tempo.

Corroborando com o exposto, destacam-se os argumentos de Petri (2005), nos quais os componentes básicos de um indicador não dizem o que fazer para melhorar, mas oferecem relações numéricas que refletem uma situação atual proporcionando informações que permitam um alinhamento efetivo na organização. Oliveira (2010) descreve os principais indicadores de desempenho utilizados pelas empresas, conforme o Quadro 3, a seguir: 


\begin{tabular}{|c|c|c|}
\hline $\begin{array}{l}\text { Perspec- } \\
\text { tiva }\end{array}$ & Indicador & Características \\
\hline \multirow{4}{*}{ Financeira } & $\%$ Crescimento da receita & $\begin{array}{l}\text { Mede o percentual da receita no período atual divido } \\
\text { pelo total da receita do período anterior. }\end{array}$ \\
\hline & $\%$ Margem bruta & $\begin{array}{l}\text { Mede o equilíbrio entre a receita e a despesa da empresa } \\
\text { analisada. }\end{array}$ \\
\hline & \% Geração de Caixa & $\begin{array}{l}\text { Mede o equilíbrio entre valores a receber e as contas a } \\
\text { pagar, bem como a velocidade do fluxo de caixa. }\end{array}$ \\
\hline & Liquidez corrente & $\begin{array}{l}\text { Mede a capacidade da empresa em saldar seus } \\
\text { compromissos. }\end{array}$ \\
\hline \multirow{4}{*}{ Clientes } & $\%$ Fidelidade & $\begin{array}{l}\text { Mede a base de clientes que é regular na empresa } \\
\text { analisada. }\end{array}$ \\
\hline & $\%$ Imagem & $\begin{array}{l}\text { Mede o percentual de entrevistados que têm uma visão } \\
\text { positiva da empresa. }\end{array}$ \\
\hline & \% Manifestações dos clientes & $\begin{array}{l}\text { Mede o percentual de entrevistados que têm visão } \\
\text { positiva da empresa. }\end{array}$ \\
\hline & $\%$ Conquista de novos clientes & $\begin{array}{l}\text { Mede o número de novos clientes por segmento de } \\
\text { mercado. }\end{array}$ \\
\hline \multirow{4}{*}{ Processos } & $\begin{array}{l}\text { \% Conformidade dos serviços em } \\
\text { relação ao padrão }\end{array}$ & $\begin{array}{l}\text { Mede o percentual de serviços dispensados na qualidade } \\
\text { estabelecida. }\end{array}$ \\
\hline & \% Eficiência Operacional & $\begin{array}{l}\text { Mede o percentual utilizado da capacidade de } \\
\text { atendimento instalada. }\end{array}$ \\
\hline & \% Desperdício & $\begin{array}{l}\text { Mede o percentual de horas de retrabalho em relação ao } \\
\text { total de horas programadas. }\end{array}$ \\
\hline & $\begin{array}{l}\% \text { Conformidade do processo } \\
\text { crítico }\end{array}$ & $\begin{array}{l}\text { Mede o número de não conformidades do processo que } \\
\text { é crítico na busca de resultados efetivos. }\end{array}$ \\
\hline \multirow{4}{*}{ Aprendizado } & \% Aceitação de novos serviços & $\begin{array}{l}\text { Mede o percentual de serviços realizados em relação } \\
\text { ao previsto. }\end{array}$ \\
\hline & $\%$ Conformidade de procesos & $\begin{array}{l}\text { Mede quantidade de não conformidades em relação aos } \\
\text { processos estabelecidos. }\end{array}$ \\
\hline & $\begin{array}{|lr|}\text { \% Receita obtida por novos } \\
\text { serviços }\end{array}$ & $\begin{array}{l}\text { Mede o percentual da receita obtida com novos serviços } \\
\text { lançados. }\end{array}$ \\
\hline & \% Geração de ideias & Mede ideias aproveitadas em relação às geradas. \\
\hline
\end{tabular}

Quadro 3 - Principais indicadores de desempenho utilizados nas organizações

Fonte: adaptado de Oliveira (2010, p. 214-217).

Portanto, ao considerar a gestão dos indicadores como instrumento facilitador da Administração Estratégica por Resultados, é cabível analisar o alinhamento estratégico entre empresas terceirizadas e uma distribuidora de energia elétrica a partir da gestão de indicadores de desempenho, constituindo, portando, o objeto de estudo da parte empírica deste artigo.

\section{METODOLOGIA}

A metodologia utilizada no desenvolvimento deste trabalho contempla uma pesquisa descritiva, cuja fase empírica é orientada por uma base de dados secundária, em que constam informações provenientes de pesquisa de monitoramento de indicadores de 12 empresas terceirizadas de uma distribuidora de energia elétrica, além das informações da pesquisa de clima de 1800 colaboradores. A pesquisa primária foi aplicada nos anos de 2013 e 2014 para avaliar o nível de alinhamento estratégico em prestadoras de serviços e a empresa contratante por meio do modelo de indicadores de desempenho compatível com a proposta. Barreto (2005) 
A Distribuidora de Energia Elétrica DEE é uma grande empresa de sociedade de capital aberto. Possui aproximadamente 31 milhões de clientes distribuídos por $184 \mathrm{mu}-$ nicípios, conta com 1.200 colaboradores próprios e aproximadamente 5.000 colaboradores distribuídos em 45 empresas terceirizadas. As atividades executadas pelas empresas terceirizadas estão diretamente ligadas tanto à atividade-meio quanto à atividade-fim da DEE. $\mathrm{O}$ critério de seleção dos dados na pesquisa secundária compreendeu empresas com maior complexidade no grau de atividade e empresas com maior quantidade de funcionários.

Nesse contexto torna-se imperativa a necessidade de alinhar os objetivos das contratadas aos da contratante com foco na melhoria contínua e na geração de valor. Barreto (2005) identificou cinco dimensões que interagem intrinsecamente no ramo de distribuição e operacionalização da energia elétrica; a Figura 1 representa essa relação dinâmica de perspectiva de causa e efeito.
Analisando estas perspectivas, é possível visualizar os elementos do Balanced scorecard proposto por Kaplan e Norton (2004), complementados por um aspecto essencial a esse ramo de atividade, o qual foi identificado por aquele autor como relacionamento com os fornecedores de serviço. Sob essa ótica, no levantamento aplicado às empresas terceirizadas, Barreto (2005) propôs o modelo de avaliação por indicadores que foi adaptado para utilização na DEE.

O referido modelo baseia-se na seleção de objetivos ligados diretamente à estratégia da empresa, a partir do qual são elencados indicadores. Por fim, os executivos de média e alta gestão avaliam as metas aceitáveis para cada um desses indicadores, o que pode variar conforme cada organização. Por fim, é utilizada uma técnica denominada Método de Mudge, para definir o percentual de participação de cada indicador e objetivo na formação da nota final da empresa.

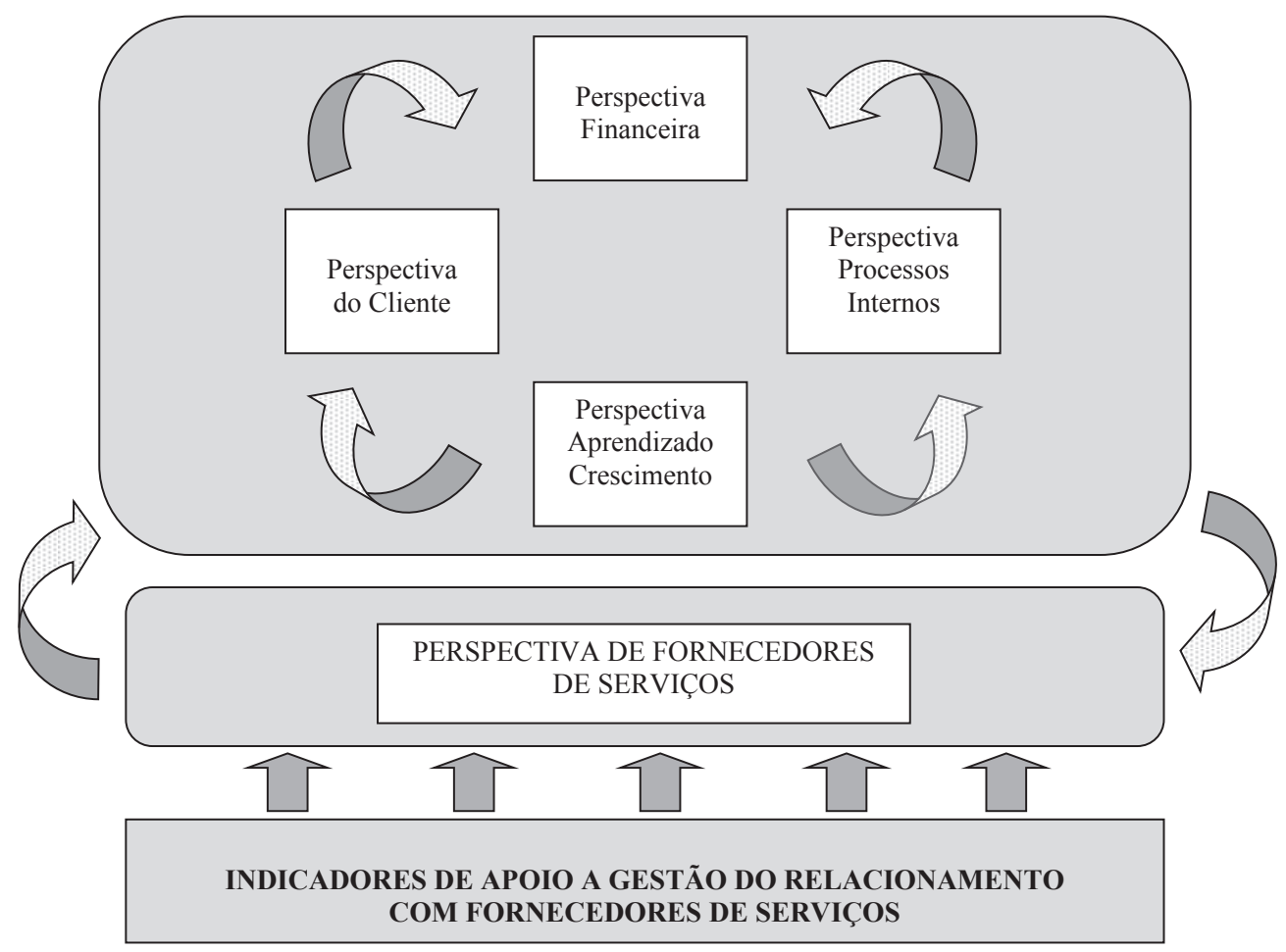

Figura 1 - Integração de estratégia de Fornecedores de Serviços e sua Contratante. Fonte: adaptado de Barreto (2005, p.42) 
Para a realização deste trabalho, foram utilizadas informações coletadas entre os anos de 2013 e 2014. A partir do processamento das informações disponibilizadas pela organização, foram consideradas cinco dimensões de avaliação nas empresas terceirizadas e seus resultados esperados, a saber:

a) melhorar a qualificação e satisfação dos colaboradores;

b) reduzir os índices de acidentabilidade no trabalho; c) melhorar a gestão das parceiras;

d) melhorar a satisfação do cliente e a qualidade dos serviços contratados e;

e) implementar a gestão com responsabilidade socioambiental.

Acrescente-se que, a cada objetivo foram atribuídos de um a cinco indicadores de desempenho. O Quadro 4 exemplifica a estrutura metodológica de maneira geral, com objetivos, indicadores e dados percentuais de cada indicador para a nota final:

\begin{tabular}{|c|c|c|c|c|c|c|}
\hline $\begin{array}{l}\text { EMPRESA: } \\
\text { PERÍDO: } \\
\text { TIPO: }\end{array}$ & $\begin{array}{l}\text { Empresa } 28 \\
\text { INPAR_2013.3 } \\
\text { SEM RISCO NA ATIVIDADE }\end{array}$ & & & & & \\
\hline DESAFIO & INDICADOR & PESO & VALOR OBTIDO & PONTUAÇÃO & $\begin{array}{l}\text { PONTUAÇÃO } \\
\text { FINAL }\end{array}$ & $\begin{array}{l}\text { TOTAL P/ } \\
\text { DESAFIO }\end{array}$ \\
\hline \multirow{4}{*}{$\begin{array}{l}\text { 1. Melhorar a } \\
\text { Qualificação e } \\
\text { Satisfação dos } \\
\text { Colaboradores }\end{array}$} & 1.1. Clima Laboral & $12 \%$ & $80,80 \%$ & 8,0 & 9,60 & \multirow{2}{*}{ Obtido } \\
\hline & 1.2. Valores & $5 \%$ & 8,29 & 8,3 & 4,15 & \\
\hline & 1.3. Rotatividade & $3 \%$ & $20,4 \%$ & 8,00 & 2,40 & 21,15 \\
\hline & 1.4. Avaliação do conhecimento & $5 \%$ & $90,0 \%$ & 10,00 & 5,00 & 25 \\
\hline \multirow{4}{*}{$\begin{array}{l}\text { 2. Reduzir os Índices } \\
\text { de Acidentabilidade } \\
\text { no trabalho }\end{array}$} & 2.1. Taxa de Frequência (Tf) & $7,5 \%$ & 0 & 10 & 7,50 & \multirow[b]{2}{*}{ Obtido } \\
\hline & 2.2. Multa por Desconformidade & $7,5 \%$ & $0 \%$ & 10 & 7,50 & \\
\hline & 2.3. IPAL & $0,0 \%$ & 0,00 & 10,00 & 0,00 & 20,00 \\
\hline & 2.4. Plano Anual de Segurança & $5 \%$ & FOI ENTREGUE & 10,00 & 5,00 & 20 \\
\hline \multirow{5}{*}{$\begin{array}{l}\text { 3. Gestão das } \\
\text { Parceiras }\end{array}$} & 3.1. Relatório de Gestão & $10 \%$ & 9,23 & 9,23 & 9,23 & \multirow{2}{*}{ Obtido } \\
\hline & 3.2. Grau de Risco & $5 \%$ & Sem Atraso & 10,00 & 5,00 & \\
\hline & 3.3. Demanda Trabalhista & $4 \%$ & 10,00 & 10,00 & 4,00 & \multirow[b]{2}{*}{19,72} \\
\hline & 3.4. SERASA / Outros & $3 \%$ & $\begin{array}{l}\text { Nome Exposto no } \\
\text { SERASA }\end{array}$ & 0,00 & 0,00 & \\
\hline & $\begin{array}{l}\text { 3.5. Auditoria Fiscal e } \\
\text { Financeira }\end{array}$ & $3 \%$ & 4,95 & 4,95 & 1,49 & 25 \\
\hline \multirow{4}{*}{$\begin{array}{l}\text { 4. Melhorar a } \\
\text { Satisfação do Cliente } \\
\text { e a Qualidade dos } \\
\text { Serviços } \\
\text { Contratados }\end{array}$} & 4.1. Índice de Satisfação & $3 \%$ & 10,0 & 10,00 & 3,00 & \multirow[t]{3}{*}{ Obtido } \\
\hline & $\begin{array}{l}\text { 4.2. Índice de Pesquisa } \mathrm{p} / \\
\text { Empresa - Junto ao Cliente }\end{array}$ & $10 \%$ & $95,7 \%$ & 10,0 & 10,00 & \\
\hline & $\begin{array}{l}\text { 4.3. Avaliação pelo Gestor de } \\
\text { Contrato }\end{array}$ & $10 \%$ & 9,26 & 9,26 & 9,26 & \\
\hline & 4.4. Inovação & $2 \%$ & 8,25 & 8,25 & 1,65 & 25 \\
\hline \multirow{3}{*}{$\begin{array}{l}\text { 5. Gestão com } \\
\text { Responsabilidade } \\
\text { Socioambiental }\end{array}$} & \multirow{3}{*}{$\begin{array}{l}\text { 5.1. Responsabilidade } \\
\text { Socioambiental }\end{array}$} & \multirow{3}{*}{$5 \%$} & \multirow{3}{*}{7,86} & \multirow{3}{*}{7,86} & \multirow{3}{*}{3,93} & Obtido \\
\hline & & & & & & 3,93 \\
\hline & & & & & & 5 \\
\hline \multicolumn{6}{|c|}{ Total Geral } & 88,70 \\
\hline
\end{tabular}

Quadro 4 - Representação genérica do modelo empregado neste trabalho Fonte: dados da pesquisa (2014).

No desenvolvimento do estudo, utiliza-se, como instrumento para organizar a coleção de dados secundários, um roteiro estruturado em três partes; a primeira contém informações acerca dos objetivos da contratante (já citados os cinco mais relevantes) e indicadores de desempenho das terceirizadas, uma vez que Barreto (2005) afirma ser necessário à concessionária integrar os fornecedores de serviços à sua estratégia, tornando claro para aqueles o seu papel no alcance dos objetivos estratégicos da empresa.

Em um segundo momento, procurou-se extrair a evolução dos resultados dos principais indicadores, dentro dos valores que a empresa define como meta. É essencial fazer essa comparação entre os dois períodos para perceber 
evolução ou involução nos esforços de gestão. Petri (2005) reafirma que os componentes básicos de um indicador, apesar de não dizerem o que fazer para melhorar, oferecem relações numéricas que refletem uma situação presente, propiciando informações capazes de redirecionar para o alinhamento efetivo na organização.

Por fim, na terceira parte, evidencia-se por meio de uma nota final, calculada a partir dos resultados individuais de cada empresa, baseado no modelo de Barreto (2005). Nesta etapa, fica evidente o grau de alinhamento estratégico entre empresas terceirizadas e a distribuidora de energia elétrica, possibilitando inclusive a elaboração do ranking de desempenho dentre as doze empresas que participaram do levantamento, conforme veremos mais à frente.

\section{ANÁLISE DOS RESULTADOS}

\subsection{OBJETIVOS DA CONTRATANTE E INDICADORES DE DESEMPENHO DAS TERCEIRIZADAS}

O primeiro objetivo é melhorar a qualificação e a satisfação dos colaboradores; esse objetivo visa melhorar o baixo grau de mão de obra qualificada encontrada no mercado para a execução das atividades contratadas, o que impacta na segurança no trabalho. Outro ponto importante é o comprometimento dos colaboradores terceirizados, pois sua satisfação no trabalho é primordial para um serviço de qualidade. Os indicadores que constam nesse objetivo são: clima laboral, valores, rotatividade e avaliação de conhecimento.

O objetivo de número dois, melhorar os índices de acidentabilidade no trabalho visa direcionar as empresas contratadas a focar na segurança no trabalho. O resultado deste objetivo também influencia diretamente na satisfação do colaborador e na imagem da empresa. Os indicadores que constam nesse objetivo são: taxa de frequência, taxa de gravidade, multa por desconformidade, índice de prevenção de acidentes laborais e plano anual de segurança.

O terceiro objetivo que é melhorar a gestão das parceiras busca estimular a qualidade da gestão da empresa terceirizada, assim como a redução dos problemas de ordem financeira, pois quando da existência de passivos trabalhistas, estes se propagam até a contratante e podem causar, além de danos financeiros, desgastes da imagem e insatisfação do cliente. Os indicadores que constam deste objetivo são: qualidade da gestão, grau de risco, demanda trabalhista, SERASA e auditoria fiscal e financeira.

O penúltimo objetivo, melhorar a satisfação do cliente e a qualidade dos serviços contratados é um fator preponderante tendo em vista que a maioria dos serviços desenvolvidos junto aos clientes é realizada por colaboradores de empresas contratadas. Os indicadores que constam nesse objetivo são: índice de satisfação, pesquisa junto ao cliente, avaliação pelo gestor de contrato e inovação.

Por fim, melhorar a gestão com responsabilidade socioambiental tem como objetivo desenvolver programas voltados para a responsabilidade socioambiental. O indicador que consta nesse objetivo é: realizar programas de alcance social e respeito ao meio ambiente.

\subsection{EVOLUÇÃO DOS PRINCIPAIS IN- DICADORES}

Para o objetivo Melhorar qualificação e satisfação dos colaboradores, exposto no Quadro 5, o indicador rotatividade (avaliação do número de admissões e desligamentos mensais de colaboradores) é utilizado com valores acumulados por trimestre. As empresas que têm uma rotatividade menor ou igual a $8,5 \%$ obtêm nota 10 ; maior que $8,5 \%$ e menor ou igual a $16,2 \%$ obtêm nota 9 ; maior que $16,2 \%$ e menor ou igual a $23,9 \%$ obtêm nota 8 : uma empresa que tenha a rotatividade maior que $65 \%$ obtém nota 0 . 


\begin{tabular}{|c|c|c|c|c|}
\hline & & & \multicolumn{2}{|c|}{ RESULTADOS } \\
\hline OBJETIVO & INDICADOR & $\begin{array}{l}\text { RESULTADO MÁXI- } \\
\text { MO A SER OBTIDO }\end{array}$ & 2013 & 2014 \\
\hline \multirow{4}{*}{$\begin{array}{c}\text { Melhorar a } \\
\text { Qualificação e } \\
\text { Satisfação dos } \\
\text { Colaboradores }\end{array}$} & Clima Laboral & \multirow{4}{*}{10,00} & 8,50 & 8,17 \\
\hline & Valores & & 7,92 & 8,01 \\
\hline & Rotatividade & & 9,33 & 9,50 \\
\hline & $\begin{array}{l}\text { Avaliação de } \\
\text { Conhecimento }\end{array}$ & & 9,83 & 9,83 \\
\hline
\end{tabular}

Quadro 5 - Objetivo Melhorar a Qualificação e Satisfação dos Colaboradores

Fonte: dados da pesquisa (2014).

As empresas utilizam indicadores para melhorar o clima laboral e o conhecimento das atividades de seus colaboradores. A partir dessa compreensão, é possível observar que do ano de 2013 para o ano 2014, o indicador clima laboral apresentou uma redução de 0,33 pontos. $\mathrm{O}$ indicador valores obteve uma pequena melhoria de um ano para o outro e, de acordo com a média das doze empresas avaliadas, o indicador de rotatividade está diminuindo, melhorando sua pontuação, cuja evolução do ano de 2013 para 2014 foi de 9,33 para 9,50 respectivamente. Por outro lado, o índice avaliação do conhecimento manteve-se estável no período analisado.

Para o segundo objetivo, Reduzir, os índices de acidentabilidade no trabalho, que po- dem ser visualizados no Quadro 6, constatou-se que, por serem empresas que possuem um alto risco em suas atividades, elas devem seguir rigorosamente todos os procedimentos de segurança. $\mathrm{O}$ indicador taxa de frequência retrata a frequência dos acidentes de trabalho trimestralmente avaliando o número de ocorrências do período em função do total de horas trabalhadas. Empresas que tiverem uma frequência de 0 a 1,5 obtêm nota 10 ; de 1,6 a 2,0 obtêm nota 8; de 2,1 a 3,0 obtêm nota 6 , e mais de 5,0 obtêm nota 0 . Nota-se que o indicador taxa de frequência no ano de 2013 para 2014, obteve uma redução de 9,58 para 8,67 . Isso mostra que a frequência dos acidentes das empresas terceirizados está diminuindo.

\begin{tabular}{|c|c|c|c|c|}
\hline & & & RES & DOS \\
\hline OBJETIVO & INDICADOR & $\begin{array}{l}\text { RESULTADO MÁXI- } \\
\text { MO A SER OBTIDO }\end{array}$ & 2013 & 2014 \\
\hline & Taxa de frequência & & 9,58 & 8,67 \\
\hline Reduzir os Índices de & $\begin{array}{c}\text { Multa por } \\
\text { Desconformidade - } \\
\text { Comitê de Sanções }\end{array}$ & & 7,17 & 8,00 \\
\hline $\begin{array}{c}\text { Acidentabilidade no } \\
\text { Trabalho }\end{array}$ & $\begin{array}{c}\text { Índice de prevenção } \\
\text { de acidentes laborais } \\
\text { (IPAL) }\end{array}$ & 10,00 & 10,00 & 10,00 \\
\hline & $\begin{array}{c}\text { Plano Anual de } \\
\text { Segurança }\end{array}$ & & 9,17 & 9,17 \\
\hline
\end{tabular}

Quadro 6 - Objetivo: Reduzir os Índices de Acidentabilidade no Trabalho Fonte: dados da pesquisa (2014).

O índice prevenção de acidentes laborais (IPAL) indica a quantidade de falhas na segurança ocorridas nas empresas terceirizadas. Essas falhas são identificadas em fiscali- 
zações realizadas trimestralmente pela empresa contratante junto a suas empresas terceirizadas com o objetivo de prevenir acidentes de trabalho. O critério de avaliação do IPAL é: empresas com de 1 a 12 falhas obtêm nota 10; de 13 a 24 falhas obtêm nota 7,5; de 25 a 80 falhas, nota 5 ; e de 81 a 400 falhas, nota 0 .

No Quadro 6, pode-se observar que o indicador IPAL continuou com nota máxima, mostrando que as empresas estão tendo poucas falhas nas fiscalizações realizadas trimestralmente. Os indicadores do Plano Anual de Segurança (o qual deve ser enviado à contratante anualmente pela contratada, com o cronograma de atividades para prevenção de acidentes) mantiveram a mesma pontuação de um ano para o outro.
O indicador grau de risco aponta o nível de responsabilidade da empresa parceira com a satisfação dos colaboradores, levantando em conta a pontualidade do pagamento da remuneração (salários, benefícios) e encargos trabalhistas (INSS e FGTS). São utilizados como critério de avaliação: as empresas que pagam o FGTS e INSS, em dia, obtêm nota 10; as empresas que pagaram em atraso, receberam nota 5 ; e as empresas que não pagaram ou não apresentaram o comprovante de pagamento, obtiveram nota 0 .

O indicador é avaliado trimestralmente e obteve uma redução elevada de 2,08 pontos do ano de 2013 para o ano de 2014, reduzindo de 10 , nota máxima, para 7,92. Essa redução evi-

\begin{tabular}{|c|c|c|c|c|}
\hline & & & RES & OOS \\
\hline OBJETIVO & INDICADOR & $\begin{array}{l}\text { RESULTADO MÁXI- } \\
\text { MO A SER OBTIDO }\end{array}$ & 2013 & 2014 \\
\hline & Relatório de Gestão & & 9,56 & 9,16 \\
\hline & Grau de Risco & & 10,00 & 7,92 \\
\hline Melhorar a Gestão das & Demanda Trabalhista & 10,00 & 8,67 & 8,17 \\
\hline & Serasa/Outros & & 6,67 & 5,83 \\
\hline & $\begin{array}{c}\text { Auditoria Fiscal e } \\
\text { Financeira }\end{array}$ & & 6,54 & 6,78 \\
\hline
\end{tabular}

Quadro 7- Objetivo: Melhorar a Gestão das Parceiras Fonte: dados da pesquisa (2014).

No objetivo de número três: Melhorar a gestão das parceiras cujos resultados encontram-se disponíveis no Quadro 7, o único indicador que não teve redução do ano 2013 para o ano 2014 foi o auditoria fiscal e financeira, o qual obteve um avanço de 6,54 para 6,78. Os demais indicadores: relatório de gestão, grau de risco, demandas trabalhistas e Serasa reduziram seus índices do ano de 2013 para o ano de 2014, o que sugere um ponto a melhorar para a manutenção da saúde financeira das empresas parceiras. dencia que as empresas terceirizadas não estão comprovando o pagamento de FGTS e INSS de seus colaboradores, impactando, assim, diretamente na insatisfação dos colaboradores e reduzindo o clima laboral da empresa. 


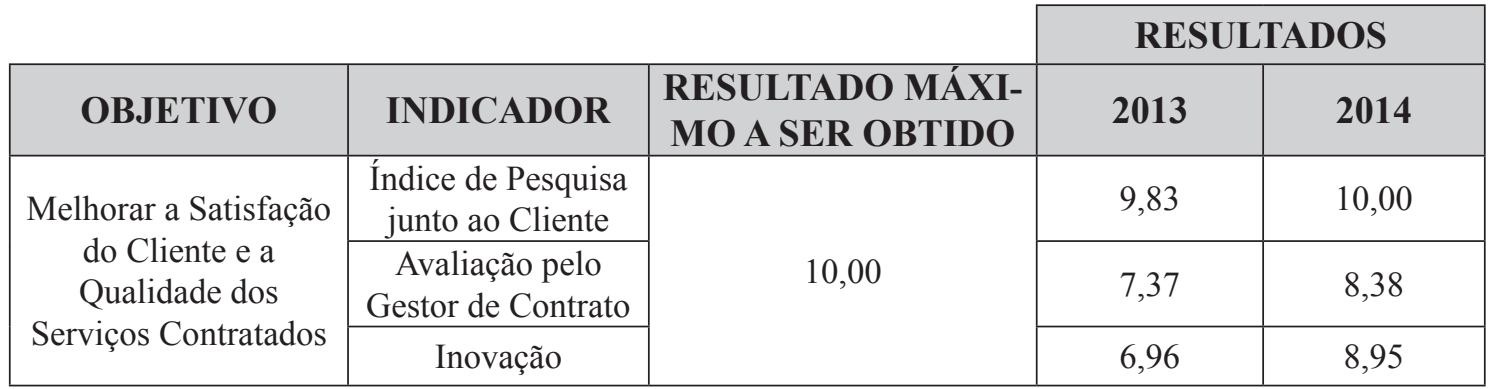

Quadro 8 - Objetivo: Melhorar a Satisfação do Cliente e a Qualidade dos Serviços Contratados Fonte: dados da pesquisa (2014).

O Quadro 8 apresenta os resultados para o quarto objetivo Melhorar a Satisfação do Cliente e a Qualidade dos Serviços Contratados pode-se dizer que, para que os indicadores desse objetivo possam dar bons resultados, esses devem estar alinhados com os objetivos anteriores, principalmente no requisito Satisfação dos Colaboradores. Isso se dá pelo fato de que os colaboradores satisfeitos geralmente fornecem serviços com maior qualidade e, consequentemente, geram clientes mais satisfeitos.

$\mathrm{O}$ indicador índice de pesquisa junto ao cliente avançou de 9,83 para 10,0, o que indica que os clientes estão cada vez mais satisfeitos com os serviços prestados pelas empresas terceirizadas. Além disso, o indicador avaliação pelo gestor de contrato teve um avanço de 7,37 para 8,38 , mostrando que os gestores da empresa contratante avaliaram melhor os serviços prestados pelos terceirizados.

As empresas terceirizadas estão buscando cada vez mais a inovação para otimizar os custos, os serviços e a qualidade nos serviços. Assim, o indicador inovação teve um considerável aumento do ano de 2013 para o ano de 2014 , de 6,96 para 8,95 .

\begin{tabular}{|c|c|c|c|c|}
\cline { 3 - 4 } \multicolumn{2}{c|}{} & \multicolumn{2}{c|}{ RESULTADOS } \\
\hline $\begin{array}{c}\text { Implementar Gestão } \\
\text { com Responsabilidade } \\
\text { Socioambiental }\end{array}$ & $\begin{array}{c}\text { Realizar programa } \\
\text { de Alcance Social } \\
\text { e Respeito ao Meio } \\
\text { Ambiente }\end{array}$ & $\begin{array}{c}\text { RESULTADO MÁXIMO } \\
\text { A SER OBTIDO }\end{array}$ & $\mathbf{2 0 1 3}$ & $\mathbf{2 0 1 4}$ \\
\hline
\end{tabular}

Quadro 9 - Objetivo: Gestão com Responsabilidade Socioambienal Fonte: dados da pesquisa (2014).

O quinto objetivo gestão com responsabilidade socioambiental, mostra um avanço de 7,2 para 8,04 pontos, conforme se constata no Quadro 9. Isso se dá pelo fato de que as empresas estão cada vez mais voltadas para compromissos éticos que podem melhorar sua imagem.

Além do exposto, podem-se destacar as seguintes ações que estão sendo desenvolvidas pelas empresas terceirizadas para a melhoria de seus resultados no compromisso com o meio ambiente: a conscientização da coleta seletiva, a utilização de sacolas ecológicas e a participação em campanhas de doação para a comunidade e instituições carentes, entre outras. 


\subsection{ALINHAMENTO DAS TERCEIRI- ZADAS COM SUA CONTRATANTE NA PERSPECTIVA DOS INDICA- DORES DE DESEMPENHO}

Os objetivos apresentados abaixo, são definidos com o intuito de alinhar as empresas terceirizadas com os objetivos da empresa contratante, de modo a apoiar a gestão do relacionamento entre ambas as partes. Esses objetivos se apoiam nas quatro perspectivas (financeira, cliente, processos e aprendizado) da contratante com foco na melhoria contínua e na geração de valor.

Pode-se observar no Quadro 10 que o alinhamento entre os objetivos da empresa contratante e os objetivos das empresas terceirizadas possibilitou uma melhoria de 8,28 para 8,51 , com ênfase no objetivo melhorar a satisfação do cliente e a qualidade dos serviços contratados que evolui de 8,05 em 2013 para 9,11 em 2014.

Além disso, as empresas terceirizadas melhoram seus indicadores da responsabilidade socioambiental mostrando um maior interesse por questões acerca do ambiente e da sociedade. parceiras, pois esse reduziu de 8,29 para 7,57. Este resultado tende a dificultar o alinhamento estratégico, já que pode impactar negativamente na satisfação dos colaboradores e no clima laboral da empresa.

\section{CONCLUSÃO}

$\mathrm{O}$ aumento da competitividade faz que as empresas busquem uma forma de melhorar os seus processos e, assim, seus resultados. Diante disso, muitas empresas optam por terceirizar seus serviços e focar-se apenas nas suas atividades principais. Apesar dessa opção, não deixa de ser necessário melhorar a sinergia entre a empresa contratante e as contratadas, uma vez que estando alinhados os objetivos e estratégias, a realização das atividades é melhorada e ocorre um ganho de desempenho em ambos os lados.

Vale mencionar que mais de $70 \%$ da força de trabalho da distribuidora de energia elétrica, objeto de análise deste estudo, é formada por colaboradores terceirizados. Nesse sentido, os objetivos e indicadores apresentados na

\begin{tabular}{|c|c|c|c|}
\cline { 3 - 3 } \multicolumn{2}{c|}{} & \multicolumn{2}{c|}{ RESULTADOS } \\
\hline OBJETIVOS & $\begin{array}{c}\text { RESULTADO } \\
\text { MÁXIMO A SER } \\
\text { OBTIDO }\end{array}$ & $\mathbf{2 0 1 3}$ & $\mathbf{2 0 1 4}$ \\
\hline $\begin{array}{c}\text { Melhorar a Qualificação e Satisfação dos } \\
\text { Colaboradores }\end{array}$ & 10,00 & 8,90 & 8,88 \\
\hline $\begin{array}{c}\text { Reduzir os Índices de Acidentabilidade no } \\
\text { Trabalho }\end{array}$ & 10,00 & 8,98 & 8,96 \\
\hline $\begin{array}{c}\text { Melhorar a Gestão das Parceiras } \\
\text { Melhorar a Satisfação do Cliente e a Qualidade } \\
\text { dos Serviços Contratados }\end{array}$ & 10,00 & 8,29 & 7,57 \\
\hline $\begin{array}{c}\text { Implementar Gestão com Responsabilidade } \\
\text { Socioambiental }\end{array}$ & 10,00 & 8,05 & 9,11 \\
\hline Média dos Objetivos & 10,00 & 7,20 & 8,04 \\
\hline
\end{tabular}

Quadro 10 - Médias dos indicadores do Desempenho dos Terceirizados Conforme os Objetivos da Contratante

Fonte: dados da pesquisa (2014).

Um dos aspectos que deve ser ressaltado é quanto ao objetivo de melhorar a gestão das pesquisa possibilitaram a identificação dos aspectos mais críticos para o alinhamento e o seu 
impacto no serviço prestado pelas terceirizadas e na satisfação do cliente final.

Assim, diante do estudo realizado junto à distribuidora de energia elétrica com doze empresas terceirizadas, verificou-se que os indicadores de desempenho que mais se destacaram, no sentido positivo, foram o índice de multas por desconformidade, com aumento de 0,83 pontos, responsabilidade socioambiental com crescimento de 0,84 pontos, as avaliações do gestor de contrato e inovação, que juntas representam um crescimento de 1,01 e 1,99 pontos respectivamente de um ano para o outro.

Quanto à identificação dos indicadores, observou-se que os mesmos são desenvolvidos por meio de objetivos estimulados pela distribuidora de energia. Assim, sugere-se que este trabalho contribuirá para que outras empresas do mesmo setor percebam os benefícios da implantação deste tipo de modelo de gestão, melhorando inclusive os resultados financeiros e de satisfação do consumidor, haja vista a modelagem dos dados e as análises realizadas convergirem para essa maior aproximação de mapas estratégicos e de ações entre as empresas parceiras: contratante e contratadas.

Diante do exposto, pode-se afirmar que o trabalho evidenciou aspectos fundamentais quanto ao alinhamento estratégico entre empresas terceirizadas e uma distribuidora de energia elétrica a partir da gestão de indicadores de desempenho. Todavia, o trabalho apresenta algumas limitações diante do tratamento dos indicadores das empresas terceirizadas serem tratados de forma agregada e não verificando a perspectiva individualizada de cada empresa contratada. Além disso, o método de estudo de caso não permite robustez que permita a generalização dos resultados. Assim sendo, sugere-se que, em pesquisas futuras, alguns objetivos e indicadores possam ser revistos e aprimorados, permitindo explorar outros fatores que influenciem no alinhamento e nos resultados organizacionais do modelo terceirizado em mais empresas e entre outros ramos de atividades no âmbito nacional.

\section{STRATEGIC ALIGNMENT OF A CONCESSIONAIRE OF ELECTRIC ENERGY DISTRIBUTION AND ITS OUTSOURCED ENTERPRISES: A DESCRIPTIVE STUDY OF POST- DEPLOYMENT PERFORMANCE INDICATORS}

\section{ABSTRACT}

In the scenario of globalization of economies, the advent of modern forms of management and communication require the adoption of new institutional models that encourage the competitiveness of Brazilian companies. Among these changes, there is the privatization of the electricity sector and the emergence of the management models for outsourcing in order to promote cost reduction, saving of resources and decentralization of activities. So, in this study the strategic alignment between outsourcing companies and a concessionaire of electric energy distribution is analyzed through performance indicators. The descriptive research was performed using a secondary database providing the information of performance indicators of 12 outsourced enterprises of a concessionaire of electric energy distribution besides the information gathered from 1800 collaborators of companies in the electricity sector. The main results show improvement of the business results of the outsourced enterprises and the distributor of electric energy, mainly because of the evaluation model that was implemented to promote closer relations between contractor and contracted allowing better timing in the strategic alignment of these companies.

Keywords: Strategic alignment. Outsourcing. Electricity sector.

\section{REFERÊNCIAS}

BARRETO, José Renato Ferreira. Modelo de apoio à gestão do relacionamento entre as concessionárias de distribuição de energia 
elétrica e as empresas fornecedoras de serviços. 2005. 141f. Tese (Doutorado em Engenharia de Produção) - Universidade Federal de Santa Catarina, Florianópolis, 2005.

CAMPOS, Gastão Wagner de Souza. Um método para análise e cogestão de coletivos. 2 . ed. São Paulo: Hucitec, 2005.

\section{CAVALCANTI, Marly. Gestão estratégica} de negócios: evolução, cenários, diagnóstico e ação. 2. ed. São Paulo: Thomson Learning, 2007.

CUMMINGS, Thomas G.; WORLEY, Christopher G. Organization developmente \& change. 10th ed. Stamford: Cengage Learning, 2015.

COSTA, Márcia S.Terceirização: velhos dilemas e a necessidade de uma nova ordem. In: Encontro da Associação Nacional de Pós-graduação e Pesquisas em Administração, 36., 2012, Rio de Janeiro. Anais... Rio de Janeiro: Anpad, 2012. p. 11-12.

D'ARAÚJO, Roberto Pereira. O setor elétrico brasileiro: uma aventura mercantil. Brasília: CONFEA, 2009.

DIAS, Taisa et al. Teoria geral da administração e teoria das organizações: uma reflexão epistemológica transpassando os dois campos. In: ENCONTRO DE ENSINO E PESQUISA EM ADMINISTRAÇÃO E CONTABILIDADE - EnEPQ, 4., 2013, Distrito Federal. Anais... Distrito Federal: EnEPQ, 2013. p. 7-8.

DUTRA, Ademar. Metodologia para avaliar e aperfeiçoar o desempenho organizacional: incorporando a dimensão integrativa à MCDA construtivista-sistêmico-sinergética. 2003. 320 f. Tese (Doutorado em Engenharia de Produção) - Programa de Pós-Graduação em Engenharia de Produção, Universidade Federal de Santa Catarina, Florianópolis, 2003.

GIOSA, Lívio Antônio. Terceirização: uma abordagem estratégica. 8. ed. São Paulo: Mec- ca, 2007.

GUIMARÃES, Cristina Machado; CARVALHO, José Crespo de. Terceirização em cuidados continuados: uma abordagem de gestão de risco. Ciênc. Saúde coletiva, Rio de Janeiro, v. 17, n. 5, p. 1179-1190, 2012. Disponível em: <http://www.scielosp.org/pdf/csc/v17n5/ a12v17n5.pdf>. Acesso em: 30 set. 2014.

HOURNEAUX JUNIOR, Flavio; RUIZ, Fernando Martinson; CORREAA, Hamilton Luiz. A evolução dos métodos de mensuração e avaliação de desempenho das organizações. In: ENCONTRO DA ASSOCIAÇÃO NACIONAL DE PÓS-GRADUAÇÃO E PESQUISAS EM ADMINISTRAÇÃO, 29., 2005, Brasília. Anais... Brasília: Anpad, 2005. Disponível em: $<$ http://www.anpad.org.br/diversos/trabalhos/ EnANPAD/enanpad 2005/ESO/2005 ESOA1696.pdf $>$. Acesso em: 20 fev 2016.

KAPLAN, Robert; NORTON, David. Organização orientada para a estratégia. Rio de Janeiro: Campus, 2000.

KAPLAN, Robert; NORTON, David. Kaplan e Norton na prática. 11. ed. Rio de Janeiro: Elsevier, 2004.

KAPLAN, Robert; NORTON, David. Alinhamento: usando o Balanced Scorecard para criar sinergias corporativas. Rio de Janeiro: Campus Elsevier, 2006.

KARDEC, Allan; CARVALHO, Cláudio. Gestão estratégica e terceirização. Rio de Janeiro: Qualitymark, 2002.

KRUGMAN, Paul R.; OBSTFELD, Maurice. Economia internacional: teoria e política. 6 . ed. São Paulo: Pearson, 2007.

KWASNICKA, Eunice Lacava. Teoria geral da administração: uma síntese. 3. ed. São Paulo: Atlas, 2006. 
MACHADO, Márcia Machado; MACHADO, Márcio André; HOLANDA, Fernanda Marques. Indicadores de desempenho utilizados pelo setor hoteleiro da cidade de João Pessoa/ PB: um estudo sob a ótica do Balanced scorecard. Revista Turismo - Visão e Ação, Santa Catarina, v. 9, n. 3, p. 393-406, set./dez. 2007.

MARCELINO, Paula. Afinal, o que é terceirização? em busca de ferramentas de análise e de ação política. Revista Pegada, São Paulo, v. 8, n. 2 , p. 55-70, dez. 2007.

MIRANDA, Pedro Martins. A metodologia de gestão da terceirização para a melhoria dos serviços: estudo de caso em uma empresa de distribuição e comercialização de energia elétrica. 2011. 101f. Trabalho de Conclusão de Curso (Graduação) - Universidade de Fortaleza, Fortaleza, 2011.

NASCIMENTO, Sabrina do; BORTOLUZZI, Sandro César; DUTRA, Ademar. Mapeamento dos indicadores de desempenho organizacional em pesquisas da área de administração, ciências contábeis e turismo, no período de 2000 a 2008. In: ENCONTRO DA ASSOCIAÇÃO NACIONAL DE PÓS-GRADUAÇÃO E PESQUISAS EM ADMINISTRAÇÃO, 33., 2009, São Paulo. Anais... São Paulo: Anpad, 2009. p. 2-2.

OLIVEIRA, Djalma de Pinho Rebouças de. Gestão para resultados: atuação, conhecimentos Habilidades. São Paulo: Atlas. 2010.

OLIVEIRA, Djalma de Pinho Rebouças. Planejamento estratégico. São Paulo: Atlas, 2008.

PETRI, Sérgio Murilo. Modelo para apoiar a avaliação das abordagens de gestão de desempenho e sugerir aperfeiçoamentos: sob a ótica construtivista. 2005. 236f. Tese (Doutorado em Engenharia de Produção) - Universidade Federal de Santa Catarina, Florianópolis, 2005.
REZENDE, José Francisco de Carvalho. Alinhamento estratégico, performance balanceada e valor. In: ENCONTRO DA ASSOCIAÇÃO NACIONAL DE PÓS-GRADUAÇÃO E PESQUISAS EM ADMINISTRAÇÃO, 33., 2009, São Paulo. Anais... São Paulo: Anpad, 2009. p. 2-3.

ROSSETTI, José Paschoal; ANDRADE, Adriana. Governança Corporativa: fundamentos, desenvolvimentos e tendências. 3. ed. São Paulo: Atlas, 2012.

VALENÇA, Myrian Constantino de Almeida; BARBOSA, Allan Claudius Queiroz. A terceirização e seus impactos: um estudo em grandes organizações de Minas Gerais. Revista de Administração Contemporânea, Rio de Janeiro, v. 6, n. 1, jan./abr. 2002. Disponível em: $<$ http://www.scielo.br/scielo.php?script=sci_arttext\&pid=S1415-65552002000100010\& $\operatorname{lng}=\mathrm{pt} \& \mathrm{nrm}=\mathrm{iso} \& \mathrm{t} \operatorname{lng}=\mathrm{pt}>$. Acesso em: 20 fev. 2016.

VREULS, Etienne Hubert; JOIA, Luiz Antonio. Proposição de um modelo exploratório dos fatores relevantes para o desempenho profissional do CIO brasileiro. Revista de Administração, São Paulo, v. 47, n. 2, p. 307-324, abr./jun. 2012. 